\title{
DISMIELINIZAÇÕES PRIMÁRIAS NO SISTEMA NERVOSO CENTRAL
}

\author{
Orlando Ainar *
}

Característica comum e fundamental das doenças dismielinizantes é a degeneração primária das fibras nervosas no sistema nervoso central, independente de lesões das células nervosas ou dos vasos. Outras alterações, como necrose, gliose, infiltrados inflamatórios, etc., aparecem isoladas ou associadas em duas ou mais dessas doenças, ou em variantes de cada uma destas. A extensão e o grau dessas alterações, a predileção localizatória e a idade em que incidem, influenciadas de vários modos pela intensidade do agente causal, constituição e estado de receptividade do paciente, etc., dependerão de fatôres ainda desconhecidos, e são outros tantos motivos das numerosas variações que existem de caso para caso. As transições de uma para outra dessas doenças freqüentemente são apenas quantitativas, e não é muito rara, em um mesmo caso, a concomitância de quadros tidos como de doenças diferentes.

Por êsses motivos, numerosos patologistas têm tentado ıeunir as doenças dismielinizantes primárias em um só grupo, atribuindo-lhes patogenia semelhante, embora admitindo diversidade de fatôres etiológicos desencadeantes. Para êsses autores, o mecanismo responsável pelas lesões seria de natureza alérgica. Fundamentam-se, para tanto, em argumentos ponderáveis e demonstrações experimentais sugestivas. Outras autoridades não reconhecem a validez da teoria alérgica $\mathrm{e}$ invocam argumentos também respeitáveis. A verdade é que os fatôres causais dessas doenças continuam ignorados. Tem-se incriminado também, como seus agentes, as reações tóxicas; as infecções, ação de enzimas lipolíticas, distúrbios vasculares, etc.

Experimentalmente, $\mathrm{\epsilon m}$ animais de laboratório, têm sido provocadas dismielinizações de várias maneiras, sem que os quadros obtidos correspondam exatamente aos observáveis nas doenças humanas. Porém, o fato de serem essas experiências feitas em animais já justificaria algumas dessas diferenças. Acresce que, mesmo entre as várias espécies, há diversidade de reações a tal ou qual agente mórbido. Considere-se também que, na experimentação, as condições nunca reproduzem exatamente as naturais.

'Trabalho apresentado no Departamento de Neuro-Psiquiatria da Associação Paulista de Medicina, em 8 agôsto 1951.

* Assistente de Anatomia: Secçòes de Neuranatomia (Dep. de Anatomia: Prof. R. Locchi) e Neuropatologia (Dep. de Anatomia Patológica: Prof. L. Cunha Motta) da Fac. Med. da Univ. de São Paulo. 
Dismielinizações experimentais têm sido obtidas por meio de oclusão parcial de vasos cerebrais, anóxia química, injeção de toxinas, injeção intracerebral ou extracerebral de emulsões e extratos cerebrais.

São representantes principais dessas doenças as que vêm sendo rotuladas como esclerose difusa (de Schilder), neuromielite óptica (de Devic), esclerose múltipla ou disseminada, degeneração combinada subaguda da medula, encefalomielites disseminadas pós-infecciosas e encefalomielite alérgica experimental.

Grupo "Esclerose Difusa" (fig. 1) - Na doença de Schilder e variantes encontram-se áreas extensas e difusas de destruição da substância branca dos hemisférios, com certa simetria bilateral; os nervos ópticos são afetados em muitos casos, o que também pode ocorrer, com freqüência menor, nas outras partes do neuro-eixo. Nos hemisférios, as lesões comprometem às vêzes também o córtex, mas freqüentemente o respeitam, bem como às fibras arqueadas subcorticais. Os focos lesionais podem ter, em

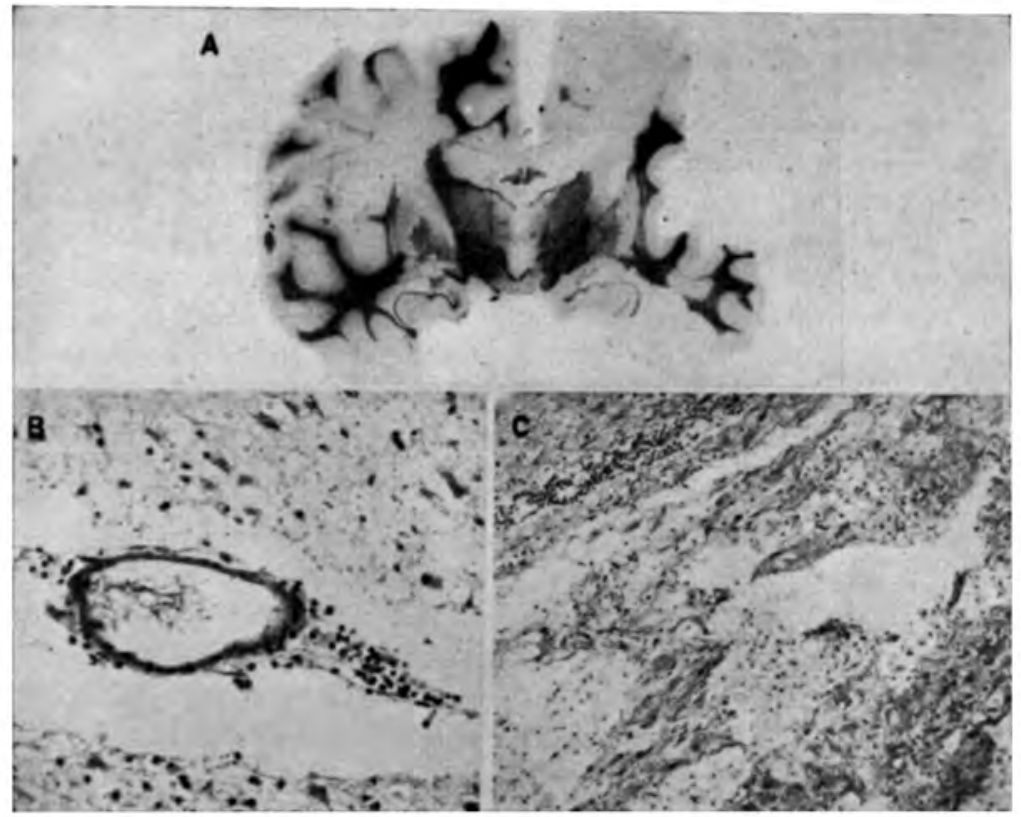

Fig. 1 - Esclerose difusa. Em A (fase crônica), extensas áreas de dismielinização em giros frontais e corpo caloso (Mét. Weil, $\times 0,5$ ). Ém B (fase crônica), gliose e, na adventícia vascular, linfócitos e Gitterzellen (H.E., $\times 360$ ). Em C (forma subaguda), massas de Gitterzellen interpostas entre traves de gliose; linfócitos e Gitterzellen perivasculares no angulo superior esquerdo da figura (H.E., $\times 120$ ). 
um mesmo caso, caracteres diferentes: 1) Em alguns, de consistência pastosa, há amolecimento da substância branca. Apresentam enorme quantidade de corpúsculos granulares compostos (Gitterzellen) carregados de detritos e pigmento hemossiderótico, especialmente em tôrno dos vasos, de mistura então com linfócitos; os astrócitos evidenciam reação progressiva, iniciando certo grau de gliose, e muitos dêles aparecem sob a forma de Gemästetezellen ou sob a de células multinucleadas. 2) Por outro lado, como na forma clássica da doença, os focos crônicos são muito consistentes e irregulares, devido à retração cicatricial causada pela intensa gliose heteromorfa; nestes, são escassos os infiltrados perivasculares e corpúsculos granulares compostos. 3) Outros focos, enfim, representam graus de transição entre os agudos e os crônicos, com passagem gradual de predominância dos fenômenos regressivos para a das reações reparadoras.

Segundo predominem tais ou quais tipos de lesão, e em consonância com a história clínica, fala-se em formas aguda, subaguda ou crônica da doença. Parece haver certa prevalência das lesões agudas nas crianças, e das crônicas em adultos. A variabilidade de localização dos focos no neuro-eixo, da predominância de lesões agudas ou crônicas e de incidência na idade, condiciona quadros clínicos diferentes, razão por que se tem tentado considerar as variações como entidades mórbidas definidas. As formas de Baló, Krabbe, Pelizäus-Merzbacher, Scholz, etc., parecem não ser mais do que variantes da doença de Schilder, embora as últimas tenham sido descritas como de tendência familial.

Neuromielite óptica (fig. 2) - A doença de Devic se caracteriza por focos de alteração tecidual nas vias ópticas e medula espinal, sob a forma de amolecimentos e esclerose que atingem também a substância cinzenta. Essas áreas apresentam-se dismielinizadas e exibem desmantêlo da estrutura, em alguns casos com grande número de corpúsculos granulares compostos e outras formas de microgliócitos, juntamente com oligodendrócitos e astrócitos; os primeiros formam também espessos manguitos perivasculares, de mistura com linfócitos. Em outras palavras, o quadro é então semelhante ao das lesões "agudas" da substância branca na esclerose difusa. O número de astrócitos é relativamente pequeno, e é escassa a gliose reparadora nos focos medulares. As células nervosas são afetadas em graus que variam de cromatólise até fragmentação, podendo-se encontrar satelitose e neuroniofagia. No nervo óptico e, às vêzes, na medula, a gliose pode ser intensa, quando então o quadro microscópico se superpõe ao das lesões "crônicas" da esclerose difusa de Schilder. Aliás, há alguns casos descritos em que êsse quadro se apresentou associado ao da esclerose difusa de Schilder, o que parece indicar patogenia comum destas doenças. Ainda recentemente tivemos oportunidade de verificar a ocorrência dessa associação em um de nossos casos, e presentemente estamos estudando outro em que essa "associação" é ainda mais sugestiva. 


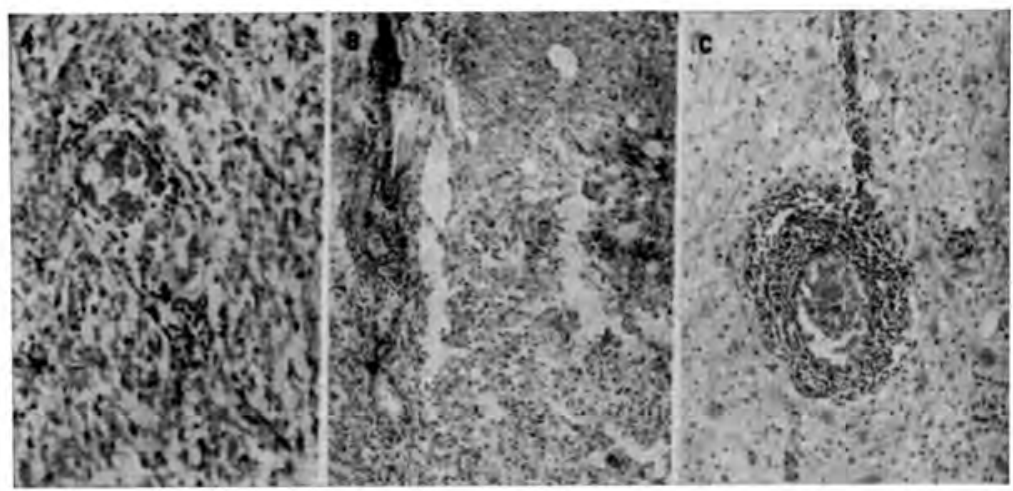

Fig. 2 - Neuromielite óptica. Em A, necrose em segmento cervical da medula, com massas de Gitterzellen, gliose escassa e infiltrado perivascular de linfócitos e Gitterzellen (H.E., $\times 120)$. Em B, nervo óptico esclerosado, com infiltrado linfocitário perivascular (H.E., $\times 360$ ). Em $C$, foco cerebral de dismielinização em outro caso de neuromielite óptica. $O$ campo de gliose é atravessado por algumas fibras nervosas íntegras. Intenso infiltrado linfocitário em tôrno do vaso maior; ao longo de seu afluente há numerosas Gitterzcllen (H.E., $\times 120)$.

Esclerose múltipla (fig. 3) - Na esclerose em placas, as manchas são disseminadas pelo neuro-eixo. Porém, as alterações patológicas não se limitam a elas, podendo ser encontradas difusamente. inclusive em raízes nervosas e, segundo alguns, em nervos periféricos. As placas são de dimensões, forma e número variados, com limites nítidos, de coloração acinzentada após fixação, consistentes, sem relações topográficas constantes com vasos, septos ou substância cinzenta. Predominam na substância branca, mas também se estendem à cinzenta, sem afetar, no entanto, as células nervosas. Diz-se serem mais freqüentes próximo aos ventrículos e substância cinzenta.

Essas placas representam a fase final das alterações; outras existem, porém, pálidas, onde a destruição tecidual é menor, e há uma fase ainda mais precoce no tecido aparentemente normal, vizinho às placas. Neste último, encontram-se algumas fibras em vias de destruição, com bainhas mielínicas entumescidas ou em início de desintegração, e cilindros-eixos irregulares, alguns já invadidos por mieloclastos (micro- ou oligondendrócitos modificados). Nas manchas em fase de transição, a mielina já está fragmentada em maior número de fibras, e há mielófagos em certa quantidade, Gitterzellen, glóbulos de Marchi, etc., e maior número de axôrios estão comprometidos; os fagócitos vão sendo impelidos para os espaços perivasculares; há certa hiperplasia dos astrócitos, com início de gliose. Finalmente, na última fase, as placas tornam-se cicatrizes de gliose intensíssima, atravessadas por alguns axônios, um ou outro coberto por hainha 
de mielina; os corpúsculos granulares compostos já alcançaram a leptomeninge, onde estão de mistura com alguns linfócitos. Alguns vasos podem apresentar paredes hialinizadas. Essas placas assemelham-se, portanto, aos focos "crônicos" de esclerose de Schilder.
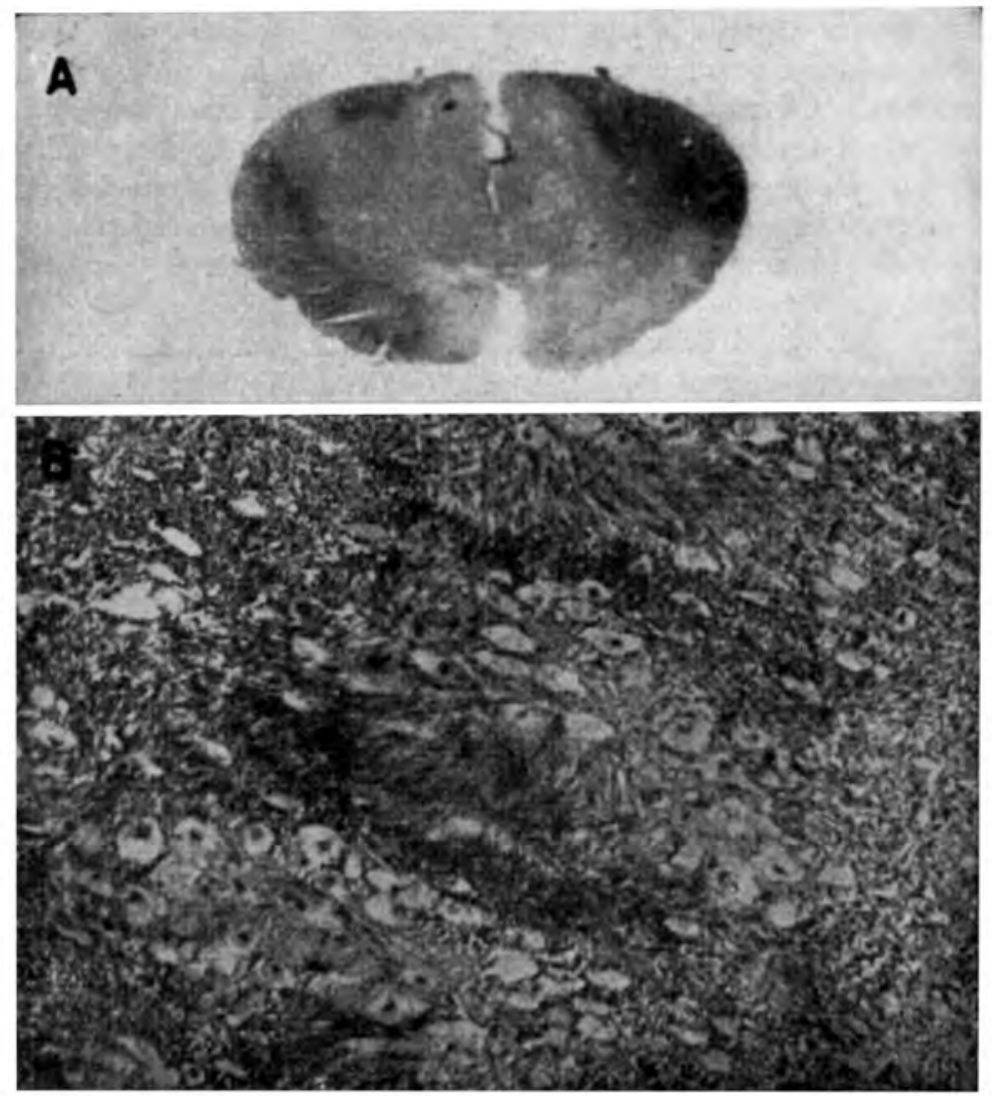

Fig. 3 - Esclerose múltipla. Em $A$, corte de medula torácica con dismielinização de grrande parte das substâncias branca e cinzenta (Mét. Weil, $\times 2,5)$. Em I3, medula torícica com grliose intensa, tendo sido focalizado um ninho de Gitterzellen (H. Fost., $\times: 360$ ).

$\mathrm{Na}$ chamada esclerose múltipla aguda os fenômenos desenvolvem-se mais ràpidamente, e os elementos inflamatórios predominam sôbre os degenerativos; o quadro lembra então o da encefalomielite disseminada aguda.

Degeneração combinada subaguda (fig. 4) - Nesta doença há lesões mais ou menos simétricas de longos tractos dos cordões dorsais e laterais da medula, por vêzes também dos ventrais; aparece, no mais das vêzes, 
em doentes de anemia perniciosa. As lesões são mais extensas nos segmentos torácicos, e não comprometem a substância cinzenta e nem as raízes medulares. Caracterizam-se por pequeninos pontos de necrose conjunta das bainhas mielínicas, cilindros-eixos e glia, formando espaços lacunares circunscritos por fibrilas gliais escassas, o que dá às áreas afetadas um aspecto cribriforme típico (status spongiosus: Lückenfelder). Em um ou outro dêsses espaços e em tôrno dos vasos encontram-se corpúsculos granulares compostos carregados de lipóides. Não há, pràticamente, gliose reparadora. Os vasos podem ter paredes hialinizadas. Os tractos longos mais atingidos podem apresentar degeneração secundária, distalmente à sua lesão. De regra, as células nervosas não sofrem alterações, ou apresentam cromatólise conseqüente à seç̧ão de seus axônios. Segundo alguns autores, pode haver comprometimento discreto de nervos periféricos na fase inicial da doença.

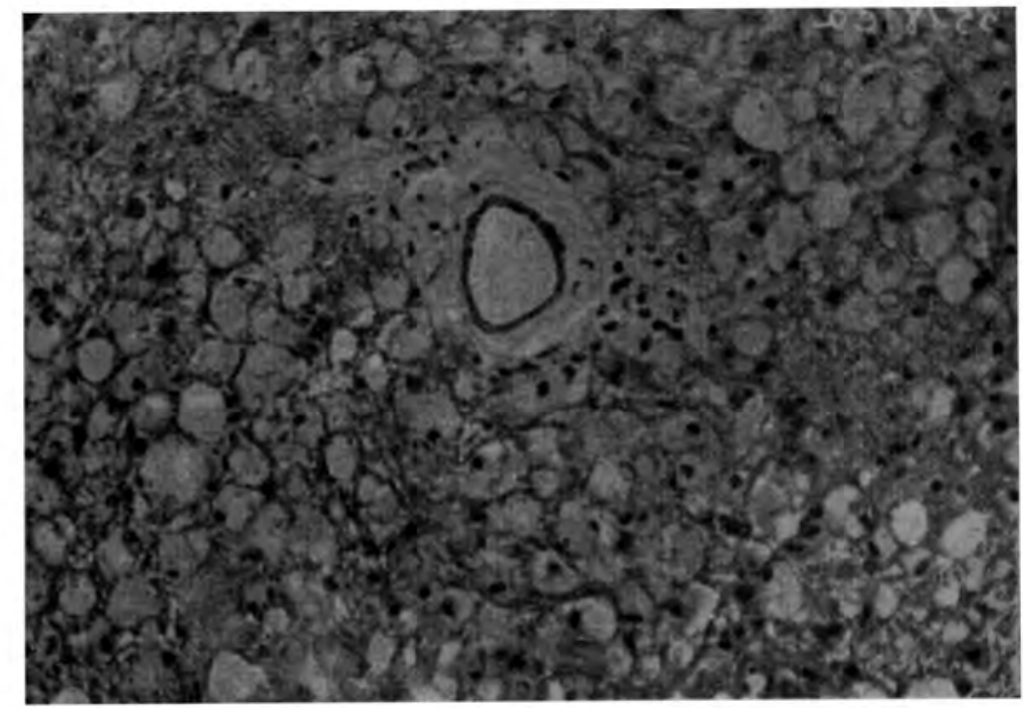

Fig. 4 - Degeneração combinada subaguda (síndrome neuranênuca). Corte de medula torácica mostrando status spongiosus, com Gitterzellen em muitas das cavidades e em tôrno do vaso (H.E., $\times 360$ ).

Dismielinizações perivasculares pós-infecciosas (fig. 5) - Referem-se às síndromes de encefalomielites disseminadas agudas relacionadas com o sarampo, vacinação, varíola e tratamento anti-ráhico, e também com febre tifóide, influenza, escarlatina, varicela, parotidite epidêmica, herpes, etc.

Patològicamente, são mais típicas as que se seguem ao sarampo, vacinas, varíola e tratamento anti-rábico. Caracterizam-se por focos periadventiciais de dismielinização, especialmente em tôrno das veias, com des- 
truição dos axônios, hiperplasia micro- e astroglial, bem como pequena reação mesenquimal na adventícia e acúmulo de Gitterzellen; êsses focos são mais freqüentes na substância branca subcortical e subependimária, e na periferia da medula espinal. As células nervosas podem apresentar alterações que variam entre tumefação e liqüefação, e pode haver certa
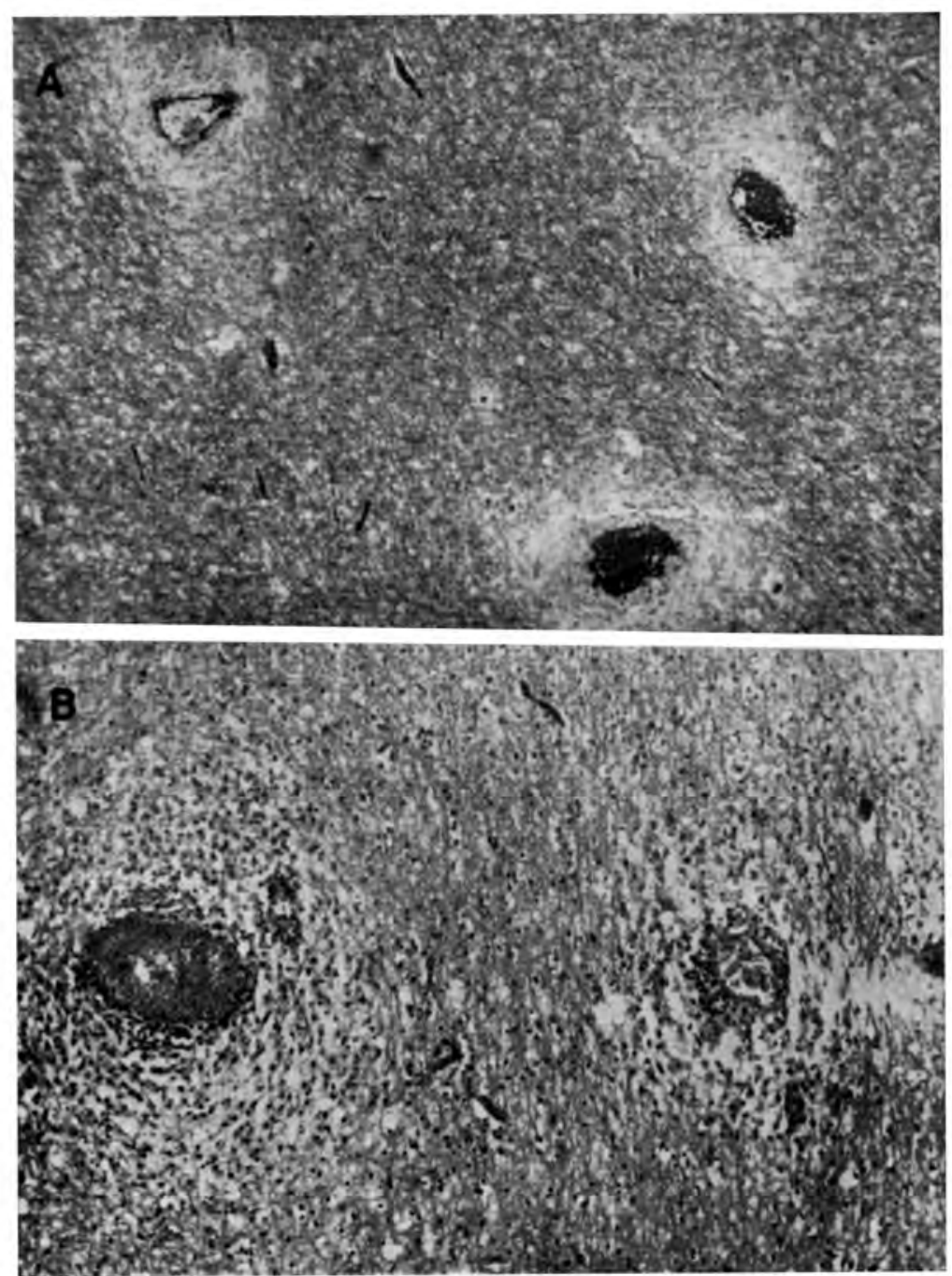

Fig. 5 - Encefalite disseminada pós-varicela. Em A, substância branca subcortical com dismielinizações perivasculares (Weil, $\times 100$ ). Em B, hiperplasia micro- $e$ astroglial periadventicial, com alguns linfócitos na adventícia dos vasos (H.E., $\times 120$ ). 
hiperplasia glial também na substância cinzenta. Os vasos ficam congestos e podem ter endolélio tumefeito, ou podem estar trombosados. O espaço subaracnóideo se apresenta distendido e contém em suas malhas discreto infiltrado linfomonocitário. Quadro histológico muito semelhante a êste é o que se obtém com mais freqüência na encefalomielite alérgica experimental.

Encefalomielite alérgica experimental (figs. 6 e 7) - Demonstra-se pela reação de fixação do complemento e teste de precipitina que a substância encefálica, em injeções parenterais, provoca a formação de anticorpos altamente específicos para o encéfalo, não só de animais da mesma espécie, como também de espécies diferentes; aliás, essa especificidade para o órgão só é sobrepujada pela que se relaciona com o cristalino. No iecido nervoso, a substância branca (como também os nervos periféricos) tem propriedade antigênica seis vêzes mais potente do que a cinzenta, e é mais ou menos essa também a predominância de mielina na substância branca.

Fazendo injeções intramusculares ou peritoniais de emulsão cerełral, com ou sem "adjuvantes". têm os experimentadores conseguido a produção

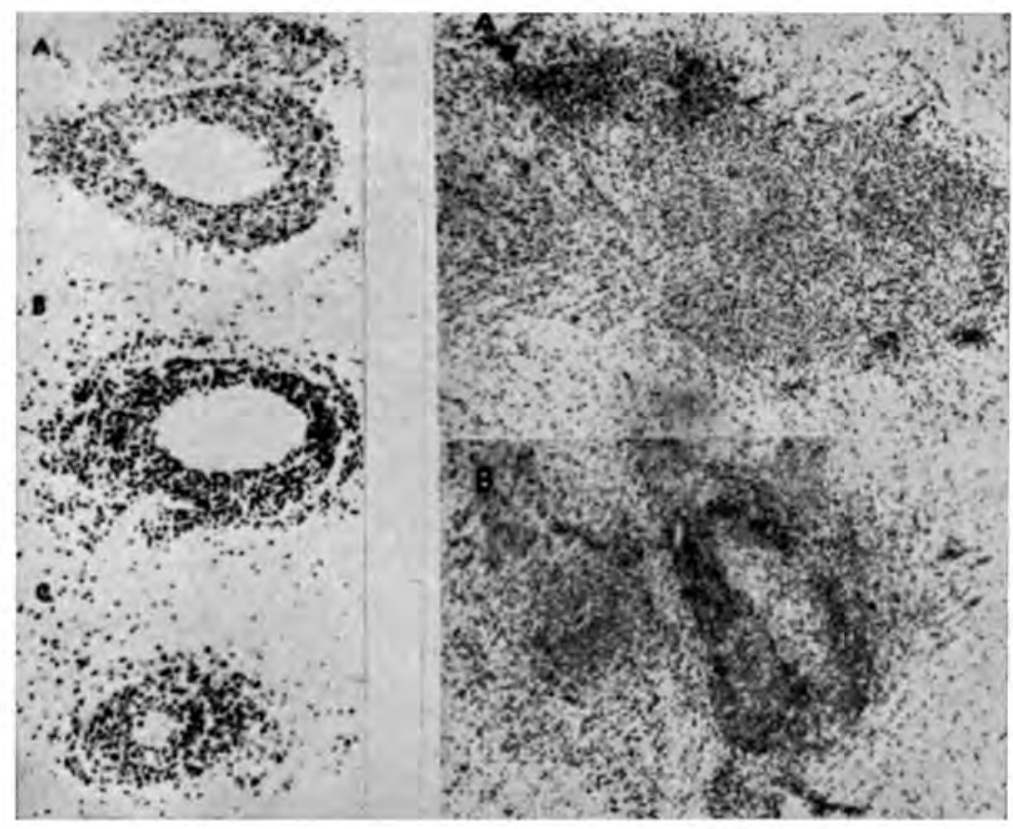

Figs. 6 e 7 - Encefalomielite alérgica experimental (Ferraro, 1944). Mét. Nissl. Em 6 , tipos de reação perivascular (A, Gitterzellen; B, linfócitos; C, mistura de ambos). Fm 7, fases inicial (A) e avançada (B) de necrose. 
de encefalomielite caracterizada por uma reação inflamatória difusa, manchas de dismielinização e, às vêzes, alguma gliose reativa. Ferraro e colaboradores, entre outros, têm conseguido quadros histológicos muito próximos daqueles que se observam nas doenças dismielinizantes humanas, quadros êsses que, em um mesmo animal, podem ser diferentes, lembrando a encefalomielite disseminada aguda em um campo, e em outros, a mielinoclase da esclerose difusa ou a da esclerose múltipla.

Aquêles investigadores foram além, procurando proteger os animais de experimentação contra a encefalomielite alérgica. Seus dados indicam certa imunização das cobaias submetidas a injeções repetidas de emulsão de encéfalo normal antes de receberem o antígeno específico que desencadeia a encefalomielite alérgica, isto é, a emulsão de encéfalo com adjuvante (à maneira de Freund).

Como se vê, parece assistir razão aos pesquisadores que vêm defendendo a unidade patogênica dêsse grupo de doenças dismielinizantes primárias do S.N.C. De fato, muitos são os elos que aproximam essas várias formas mórbidas, se bem não devamos esquecer a tendência do tecido nervoso para reagir de modos muito semelhantes a agentes etiológicos os mais diferentes. $O$ tema é brilhantemente discutido, e a bibliografia é exaustivamente revista nos trabalhos de Ferraro, Ferraro e Cazzullo. Kobb e Porta.

\section{SUMMARY}

\section{Primary Demyelinations in the Central Nervous System.}

Diffuse sclerosis, neuromyelitis optica, multiple sclerosis, subacute com. bined degeneration and acute disseminated encephalomyelitis are briefly described from the anatomical point of view, especially with reference to their variations and to those of their interlocking aspects that point to a unitary concept of their pathogeny. Their features of similarity are compared to the changes described in cases of experimental allergic encephalomyelitis (Ferraro) produced in laboratory animals.

Illustrations stress some of the features that are common to those diseases, either in their "typical" or "atypical" forms.

\section{BIBLIOGR.AFIA}

1. Alvord, E. C. e Stevenson, 1. D. - Experimental production of encephalomyelitis in guinea pigs. Res. Publ. Ass. Nerv. a. Ment. Dis., 28:99-112, 1950.

2. Ferraro, A. - a) Primary demyelinating processes of the central nervous system. A rch. Neurol. a. P'sychiat., 37:1100-1160, 1937. b) Pathology. of demyelinating diseases as an allergic reaction of the brain. Arch. Neurol. a. Psychiat., 52:443-483, 1944. 
3. Ferraro, A. e Cazzullo, C. L. - Encefalomielite allergica sperimentale e tentativi di prevenzione della stessa. Sist. Nerv., ?(6):413-419, 1950.

4. Finley, K. H. - The pathology and pathogenesis of encephalomyelitis associated with vaccination and the exanthemas. Res. l'ubl. Assoc. Nerv. a. Ment. Dis., 28:341-356, 1950.

5. Kabat, E. A., Wolf, A. e Bezer, A. E. - Experimental studies on acute disseminated encephalomyelitis in rheaus inonkey. Res. Publ. Assoc. Nerv. a. Ment. Dis., 28:113-132, 1950.

6. Kolb, L. C. - The relationship of the demyelinating diseases to allergic encephalomyelitis. Medicine, 29(2):99-121, 1950.

7. Porta, V. -- Malattie demielinizzanti del sistema nervoso. Sist. Nerv., 1(3): 53-67, 1949.

Departamento de Anatomin da Fac. Med. da Univ. de São Paulo. 